\title{
Development of Phase Change Materials Based on Mixtures of Salt Hydrates Through Theoretical Prediction and Experimental Investigation
}

\author{
Christoph Rathgeber \\ Bavarian Center for Applied Energy \\ Research (ZAE Bayern) \\ Garching, Germany \\ christoph.rathgeber@zae-bayern.de
}

\author{
Henri Schmit \\ Bavarian Center for Applied Energy \\ Research (ZAE Bayern) \\ Garching, Germany \\ henri.schmit@zae-bayern.de \\ Stefan Hiebler \\ Bavarian Center for Applied Energy \\ Research (ZAE Bayern) \\ Garching, Germany \\ stefan.hiebler@zae-bayern.de
}

\author{
Peter Hoock \\ Bavarian Center for Applied Energy \\ Research (ZAE Bayern) \\ Garching, Germany \\ peter.hoock@zae-bayern.de
}

\begin{abstract}
Latent heat storage using phase change materials (PCM) provides thermal energy storage systems with high storage capacities in small temperature ranges. Most of the PCM used in applications undergo a phase change from solid to liquid and vice versa storing heat in repeated melting and crystallization processes. To select a suitable PCM, both melting and crystallization have to match the temperature range of the intended application. In the temperature range from $0{ }^{\circ} \mathrm{C}$ to $100{ }^{\circ} \mathrm{C}$, salt hydrates are generally both cheaper and offer higher volumetric melting enthalpies than comparable organic PCM. However, in certain application-relevant temperature ranges, there is a lack of PCM based on salt hydrates. Since most salt hydrates are known, mixtures of salt hydrates and salts are being investigated. In order to identify interesting mixture compositions (for example eutectics) and to reduce the experimental effort, prediction models are applied to calculate solid-liquid phase diagrams. In the research project properPCM, the modified BET model was applied to calculate solid-liquid phase diagrams of mixtures of salt hydrates and salts. Up to now, 44 ternary phase diagrams with 151 eutectics were predicted. So far, $\mathbf{4 0}$ selected predicted eutectics have been experimentally investigated via differential scanning calorimetry (DSC). 16 of the eutectics that were successfully verified via DSC were subsequently subjected to thermal cycling stability tests. Thereby, samples of about $100 \mathrm{ml}$ have been tested in self-built thermal cycling test rigs. In order to assess the thermal cycling stability, special focus is put on the visual observation of potential phase separation of the mixtures. In the future, the developed method can be applied to create PCM based on mixtures of salt hydrates for application-relevant temperature ranges.
\end{abstract}

Keywords - thermal energy storage, latent heat storage, phase change materials (PCM), salt hydrates, modified BET model

\section{INTRODUCTION}

Latent heat storage using phase change materials (PCM) provides thermal energy storages with high storage capacities in small temperature ranges. Most of the PCM used in applications are solid-liquid PCM storing heat in repeated melting and crystallization processes. In the temperature range from 0 to $100{ }^{\circ} \mathrm{C}$, salt hydrates are comparably cheap and offer high volumetric enthalpy changes [1]-[3]. However, in certain application-relevant temperature ranges, there is a lack of cost-effective and thermally cycling stable PCM based on salt hydrates [4], [5]. Since most salt hydrates are known, mixtures of two salt hydrates or mixtures of one salt hydrate and a salt (i.e. ternary mixtures of two salts and water) are being investigated. To identify interesting mixture compositions and to reduce the experimental effort, prediction models are applied to calculate solid-liquid phase diagrams.

In the research project properPCM ("Property prediction and characterization of mixtures for the development of efficient phase change materials in relevant temperature ranges"), the modified BET model was applied to calculate solid-liquid phase diagrams of mixtures of salt hydrates and salts. The modified BET model has proven to be able to predict phase diagrams of salt hydrate mixtures over a wide concentration and temperature range [6], [7]. In the project properPCM, solid-liquid phase diagrams of systems containing water and two salts with common anions or common cations have been calculated and eutectic mixtures identified. Mostly nitrate, chloride, and bromide salts were considered as base salts.

To check the calculated compositions of identified eutectics, measurements via differential scanning calorimetry (DSC) were carried out. Eutectics that were successfully verified in DSC measurements, were subsequently subjected to thermal cycling stability tests. Thermal cycling stability is an essential requirement for a thermal energy storage medium. In the case of PCM consisting of more than one component, a separation of different phases might occur during repeated melting and crystallization cycles. If phase separation occurs, a part of the material does not contribute to the melting and crystallization enthalpy any longer, thereby reducing the storage capacity of a latent heat storage system.

\section{THEORETICAL PREDICTION OF EUTECTIC MIXTURES OF SALT HYDRATES}

The prediction of eutectic mixtures of salt hydrates and salts consists of two steps. First, the calculation of solid-liquid phase diagrams of ternary systems containing two salts and water. Second, the identification of eutectic mixtures within the calculated phase diagrams and the determination of the eutectic composition and temperature. 
A. Calculation of solid-liquid phase diagrams of salt hydrates using the modified BET model

To calculate solid-liquid phase diagrams of salt hydrate mixtures, a thermodynamic model needs to predict both the water and salt activities over the concentration and temperature range of interest. In this work, calculation of liquidus temperatures is based on the law of mass action with activities derived from the modified BET model as done in [8]:

$$
\ln a_{\mathrm{s}}+n \ln a_{\mathrm{w}}=\ln K_{\mathrm{s}}
$$

with solubility constant $K_{\mathrm{s}}$ of a solid phase, salt activity $a_{\mathrm{s}}$, water activity $a_{\mathrm{w}}$, and number of moles water per mol salt $n$. Solubility constant as well as water and salt activity depend on temperature. Equation (1) applies to the liquidus temperature where solid salt hydrate or anhydrous salt is in equilibrium with saturated salt solution. The calculation of ternary solid-liquid phase diagrams of salt hydrate mixtures starts with the two binary subsystems salt $\mathrm{A}+\mathrm{H}_{2} \mathrm{O}$ and salt $\mathrm{B}+\mathrm{H}_{2} \mathrm{O}$. To determine the liquidus curve of a binary system, (1) is solved for the concentration range under investigation considering all occurring solid phases. According to Stokes and Robinson [9], the water activity $a_{\mathrm{w}}$ and the molality $m$ of concentrated salt solutions are correlated via the modified BET equation:

$$
\frac{m a_{\mathrm{w}}}{55.51\left(1-a_{\mathrm{w}}\right)}=\frac{1}{c r}+\frac{(c-1)}{c r} a_{\mathrm{w}}
$$

The energetic parameter $c$ is defined as $c=\exp (-\varepsilon / R T)$ with $\varepsilon=E_{\text {ad }}-E_{\text {cond }}$ as the difference between the energy of adsorption at the salt surface $E_{\text {ad }}$ and the condensation energy of pure water $E_{\text {cond. }}$ The parameter $r$ is interpreted as the maximum number of water molecules that can be adsorbed in the first layer at the salt surface. Voigt [8] derived an analytical expression for the salt activity via Gibbs-Duhem integration of (2):

$$
\ln a_{\mathrm{s}}=r \ln \frac{a_{\mathrm{w}}-1}{a_{\mathrm{w}}(1-c)-1}
$$

The BET parameters $c$ and $r$ are salt-specific parameters. They can be determined from the water activity of the binary systems salt $+\mathrm{H}_{2} \mathrm{O}$, which in turn can be calculated e.g. from water vapor pressure data. An extension of the BET model to ternary systems containing two salts and water was derived by Ally and Braunstein [10]. For a ternary system, the number of water molecules $X$ and $Y$ adsorbed at salt $\mathrm{A}$ and $\mathrm{B}$, respectively, are calculated by simultaneously solving (4) and (5) at given mole number $H$ of water:

$$
\begin{gathered}
X=\frac{\left(H-z_{0}\right) c_{\mathrm{A}} r_{\mathrm{A}} A}{z_{0}+\left(H-z_{0}\right) c_{\mathrm{A}}} \\
Y=\frac{\left(H-z_{0}\right) c_{\mathrm{B}} r_{\mathrm{B}} B}{z_{0}+\left(H-z_{0}\right) c_{\mathrm{B}}}
\end{gathered}
$$

with $A(B)$ as the mole number of salt $\mathrm{A}(\mathrm{B}), c_{\mathrm{A}}\left(c_{\mathrm{B}}\right)$ and $r_{\mathrm{A}}$ $\left(r_{\mathrm{B}}\right)$ as the binary BET parameters of salt A (B), and $z_{0}$ as the root of $z=X+Y$ within the range from 0 to $H$. Following this, $X$ and $Y$ are inserted into (6) to (8) to calculate the water $\left(a_{\mathrm{w}}\right)$ and salt activities $\left(a_{\mathrm{A}}, a_{\mathrm{B}}\right)$ :

$$
a_{\mathrm{w}}=\frac{H-X-Y}{H}
$$

$$
\begin{aligned}
& a_{\mathrm{A}}=\frac{A}{A+B}\left(\frac{r_{\mathrm{A}} A-X}{r_{\mathrm{A}} A}\right)^{r_{\mathrm{A}}} \\
& a_{\mathrm{B}}=\frac{B}{A+B}\left(\frac{r_{\mathrm{B}} B-Y}{r_{\mathrm{B}} B}\right)^{r_{\mathrm{B}}}
\end{aligned}
$$

To determine the liquidus surfaces of a ternary system, (1) is solved at a given composition for each solid phase using (6) to (8) for $a_{\mathrm{w}}$ and $a_{\mathrm{s}}\left(a_{\mathrm{A}}\right.$ and $\left.a_{\mathrm{B}}\right)$. As a prerequisite, the solid phases that occur in the investigated temperature and concentration range have to be known. Further details on the applied procedure to calculate solid-liquid phase diagrams of salt hydrate mixtures are given in [11].

\section{B. Identification of eutectic mixtures within ternary solid- liquid phase diagrams}

In a binary system salt $+\mathrm{H}_{2} \mathrm{O}$, eutectics correspond to the local temperature minima of the liquidus curve. Accordingly, in a ternary system salt $\mathrm{A}+$ salt $\mathrm{B}+\mathrm{H}_{2} \mathrm{O}$, ternary eutectics correspond to local temperature minima of the liquidus surfaces. A local minimum coincides with the intersection point of three boundary curves between adjacent solid phases. In addition, the temperature minima of pseudo-binary subsystems between two congruently melting solid phases correspond to pseudo-binary eutectics [12]. To illustrate the identification of eutectics within ternary solid-liquid phase diagrams, the calculated phase diagram of the system $\mathrm{LiNO}_{3}$ $+\mathrm{NH}_{4} \mathrm{NO}_{3}+\mathrm{H}_{2} \mathrm{O}$ is shown in Fig. 1. Such three-dimensional drawings with the ordinate as temperature axis and the base as the composition triangle facilitate the interpretation of solidliquid phase diagrams.

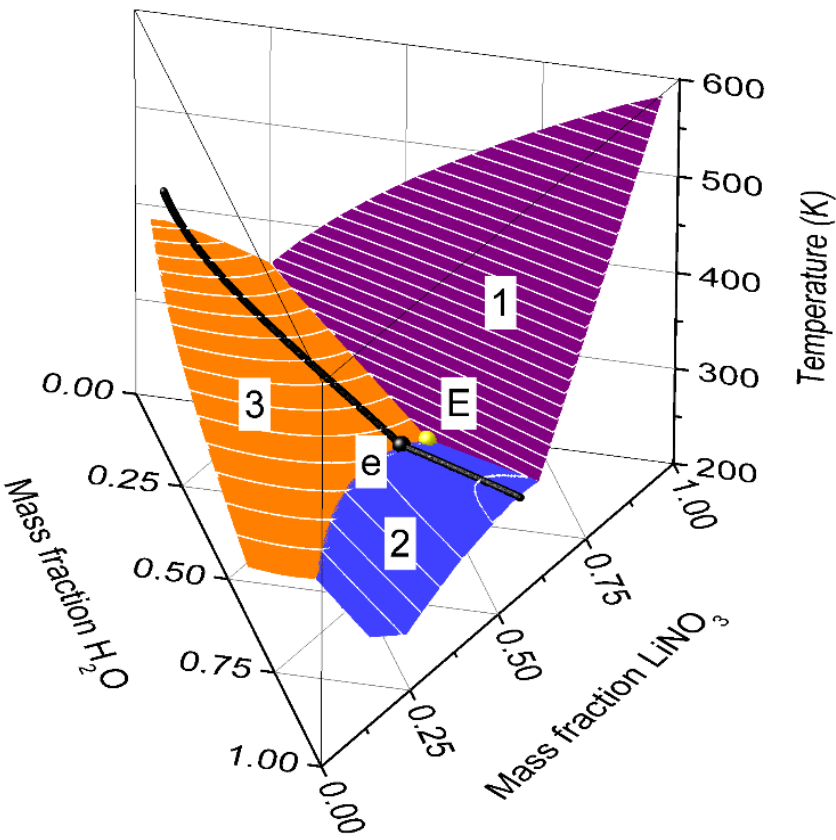

Fig. 1. Calculated solid-liquid phase diagram of the system $\mathrm{LiNO}_{3}+$ $\mathrm{NH}_{4} \mathrm{NO}_{3}+\mathrm{H}_{2} \mathrm{O}$ with ternary eutectic (E, yellow sphere), pseudo-binary subsystem (black curve), and pseudo-binary eutectic (e, black sphere); liquidus surfaces of $\mathrm{LiNO}_{3}$ (1, purple), $\mathrm{LiNO}_{3} \cdot 3 \mathrm{H}_{2} \mathrm{O}$ (2, blue), and $\mathrm{NH}_{4} \mathrm{NO}_{3}$ (3, orange)

This phase diagram was calculated using the BET parameters and solubility constants listed in TABLE I. and TABLE II. , respectively. The polymorphic crystal structures of $\mathrm{NH}_{4} \mathrm{NO}_{3}$ were considered as a single solid phase with a common solubility constant. In the system $\mathrm{LiNO}_{3}+\mathrm{NH}_{4} \mathrm{NO}_{3}$ $+\mathrm{H}_{2} \mathrm{O}$, this simplification does not affect the calculated eutectic compositions and temperatures. 
TABLE I. BET PARAMETERS OF $\mathrm{LINO}_{3} \mathrm{AND} \mathrm{NH}_{4} \mathrm{NO}_{3}$

\begin{tabular}{|c|c|c|c|}
\hline \multicolumn{1}{|c|}{ Salt } & $\boldsymbol{r} / \boldsymbol{-}$ & $\boldsymbol{\varepsilon} / \mathbf{k J} \cdot \mathbf{m o l}$ & $\mathbf{1}$ \\
\hline $\mathrm{LiNO}_{3}$ & $2.87-0.8 / 1,000 \cdot T / \mathrm{K}$ & $-6.28+0.004 \cdot T / \mathrm{K}$ & {$[7]$} \\
\hline $\mathrm{NH}_{4} \mathrm{NO}_{3}$ & 1.63 & 0.89 & {$[13]$} \\
\hline
\end{tabular}

TABLE II. SOLUBILITY CONSTANTS OF THE SOLID PHASES WITHIN THE SYSTEM LINO $3+\mathrm{NH}_{4} \mathrm{NO}_{3}+\mathrm{H}_{2} \mathrm{O}$

\begin{tabular}{|l|c|c|}
\hline \multicolumn{1}{|c|}{ Solid phase } & $\ln \boldsymbol{K}_{\mathbf{s}} /-$ & Ref. \\
\hline $\mathrm{LiNO}_{3}$ & $2.93-1,819.3 /(T / \mathrm{K})$ & {$[7]$} \\
\hline $\mathrm{LiNO}_{3} \cdot 3 \mathrm{H}_{2} \mathrm{O}$ & $12.87-6,156.6 /(T / \mathrm{K})$ & {$[7]$} \\
\hline $\mathrm{NH}_{4} \mathrm{NO}_{3}$ & $\begin{array}{c}52.45-3,587.1 /(T / \mathrm{K}) \\
-7.3 \cdot \log (T / \mathrm{K})\end{array}$ & {$[13]$} \\
\hline
\end{tabular}

In the system $\mathrm{LiNO}_{3}+\mathrm{NH}_{4} \mathrm{NO}_{3}+\mathrm{H}_{2} \mathrm{O}$, two eutectics were identified: one ternary eutectic (E) and one pseudo-binary eutectic (e). The ternary eutectic corresponds to the local temperature minimum of the liquidus surfaces of $\mathrm{LiNO}_{3}$ (surface 1 in Fig. 1), $\mathrm{LiNO}_{3} \cdot 3 \mathrm{H}_{2} \mathrm{O}(2)$, and $\mathrm{NH}_{4} \mathrm{NO}_{3}$ (3) and it is marked with a yellow sphere. Its calculated composition is $44.8 \mathrm{wt} \% \mathrm{LiNO}_{3}+28 \mathrm{wt} \% \mathrm{NH}_{4} \mathrm{NO}_{3}+27.2 \mathrm{wt} \% \mathrm{H}_{2} \mathrm{O}$. The pseudo-binary system $\mathrm{LiNO}_{3} \cdot 3 \mathrm{H}_{2} \mathrm{O}+\mathrm{NH}_{4} \mathrm{NO}_{3}$ is marked with a black curve and the temperature minimum of the pseudo-binary system (e) corresponds to the location of the pseudo-binary eutectic between $\mathrm{LiNO}_{3} \cdot 3 \mathrm{H}_{2} \mathrm{O}$ and $\mathrm{NH}_{4} \mathrm{NO}_{3}$. Its calculated composition (38.8 wt $\% \mathrm{LiNO}_{3}+30.8 \mathrm{wt} \%$ $\mathrm{NH}_{4} \mathrm{NO}_{3}+30.4 \mathrm{wt} \% \mathrm{H}_{2} \mathrm{O}$ ) is marked with a black sphere in Fig. 1.

\section{MATERIALS AND METHODS}

Samples were prepared by mixing the required amounts of salts and water. DSC measurements were performed to check the calculated compositions of identified eutectics. Eutectics that were successfully verified via DSC have been subjected to prolonged thermal cycling stability tests.

\section{A. Materials}

Anhydrous $\mathrm{LiNO}_{3}$ (99\% purity, purchased from Alfa Aesar), anhydrous $\mathrm{NH}_{4} \mathrm{NO}_{3}(>98 \%$ purity, purchased from Sigma Aldrich), and deionized water were used to prepare the samples with concentrations corresponding to the two eutectics of the ternary system $\mathrm{LiNO}_{3}+\mathrm{NH}_{4} \mathrm{NO}_{3}+\mathrm{H}_{2} \mathrm{O}$.

\section{B. Differential scanning calorimetry}

Calorimetric measurements were performed using a Q2000 heat-flux DSC from TA Instruments which was calibrated with indium as recommended by the manufacturer. The sufficiency of this single point indium calibration was verified via measurements of gallium and biphenyl in terms of temperature and deionized water in terms of enthalpy. The accuracy of the enthalpy-temperature curves determined with this DSC device has been approved in comparative studies, such as the round robin test of octadecane within the international working group IEA SHC Task 42 / ECES Annex 24 and its continuation Task 42 / Annex 29 [14] - [16]. Based on the participation in round robin tests and our experience, the enthalpy can be measured with this DSC device with an accuracy of $\pm 5 \%$ [17]. In this work, DSC measurements were carried out using $2 \mathrm{~K} \cdot \mathrm{min}^{-1}$ heating and cooling rate. A constant stream of nitrogen $\left(50 \mathrm{ml} \cdot \mathrm{min}^{-1}\right)$ was applied as flushing gas during the measurements.

\section{Thermal cycling stability tests}

The thermal cycling test setup at ZAE Bayern can be applied to thermally cycle PCM under successive melting and crystallization processes, and to visually detect an appearance variation of the material, e.g. a phase separation. Plastic laboratory bottles with a volume of $100 \mathrm{ml}$ are used as sample containers for the PCM mixtures under investigation. To perform thermal cycles, the sample containers are heated up and cooled down in a thermostatic bath without mixing actively. Usually, two to three full thermal cycles per day are carried out. Pictures of the phase transition from solid to liquid and vice versa are taken automatically and analyzed visually.

\section{RESULTS AND DISCUSSION}

\section{A. Enthalpy-temperature curves measured via DSC}

DSC measurements were performed to check the predicted compositions and temperatures of the two eutectics within the system $\mathrm{LiNO}_{3}+\mathrm{NH}_{4} \mathrm{NO}_{3}+\mathrm{H}_{2} \mathrm{O}$. The enthalpy-temperature curves of the second heating-cooling cycle are plotted in Fig. 2 and Fig. 3. Enthalpy curves upon heating are plotted as red solid lines, enthalpy curves upon cooling as blue dotted lines.

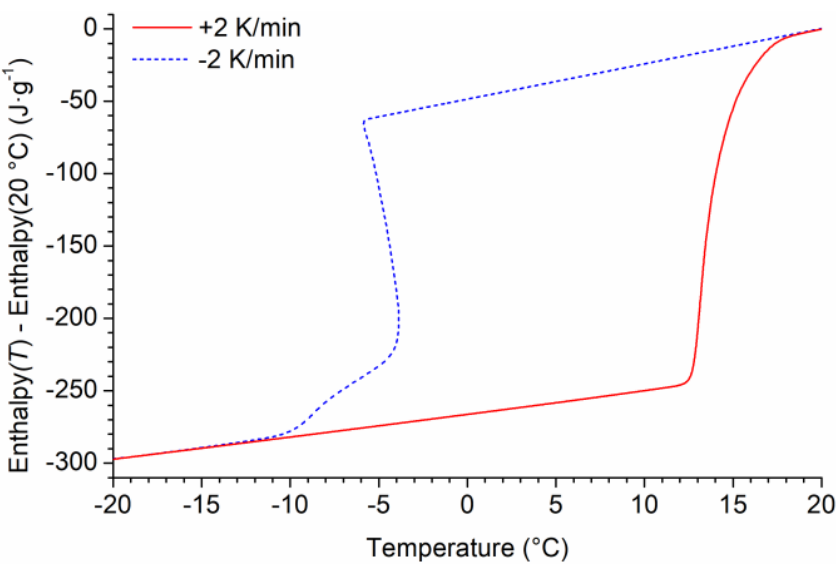

Fig. 2. Enthalpy-temperature curve of the ternary eutectic $\mathrm{E}$ within the system $\mathrm{LiNO}_{3}+\mathrm{NH}_{4} \mathrm{NO}_{3}+\mathrm{H}_{2} \mathrm{O}$ measured via DSC

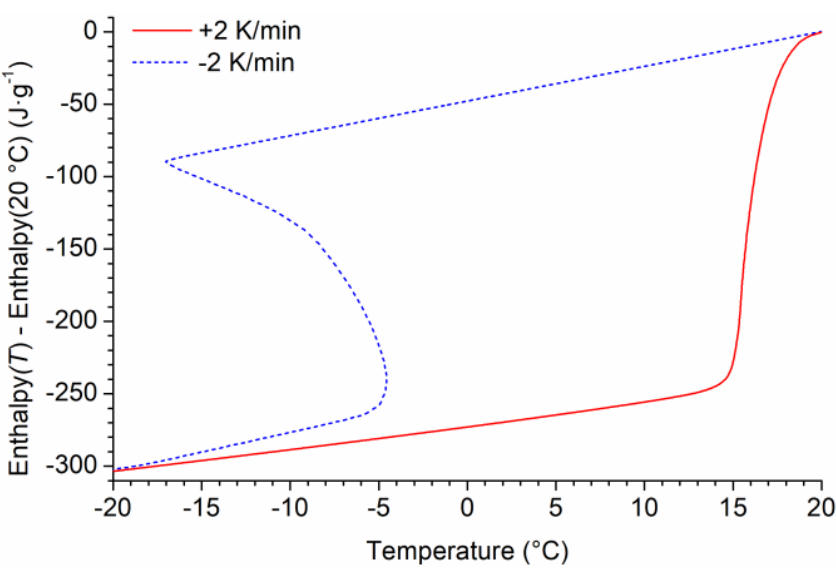

Fig. 3. Enthalpy-temperature curve of the pseudo-binary eutectic e within the system $\mathrm{LiNO}_{3}+\mathrm{NH}_{4} \mathrm{NO}_{3}+\mathrm{H}_{2} \mathrm{O}$ measured via DSC

The observed degree of supercooling is typical for DSC measurements of salt hydrates due to the small sample size of DSC crucibles. Therefore, enthalpy-temperature curves upon heating were analyzed for the verification of predicted eutectics. A single melting transition within a narrow 
temperature range is considered as a successful verification of the calculated composition of both eutectics.

The measured latent heat of fusion of ternary eutectic $\mathrm{E}$ is about $(229 \pm 11) \mathrm{J} \cdot \mathrm{g}^{-1}$ with an onset melting temperature of about $12.5^{\circ} \mathrm{C}$. The corresponding value for the pseudo-binary eutectic e is slightly higher: $(235 \pm 12) \mathrm{J} \cdot \mathrm{g}^{-1}$ with an onset melting temperature of about $14.9^{\circ} \mathrm{C}$. The expectable maximum storage capacity (MSC) corresponds to the total enthalpy difference within a specific temperature range around the phase transition, e.g. $15 \mathrm{~K}$ [18]. For the ternary eutectic and the pseudo-binary eutectic, the MSC between $5^{\circ} \mathrm{C}$ and $20{ }^{\circ} \mathrm{C}$ is about $(258 \pm 13) \mathrm{J} \cdot \mathrm{g}^{-1}$ and about $(264 \pm 13) \mathrm{J} \cdot \mathrm{g}^{-1}$, respectively.

\section{B. Thermal cycling stability of verified eutectics}

Thermal cycling stability tests of the two verified eutectics within the system $\mathrm{LiNO}_{3}+\mathrm{NH}_{4} \mathrm{NO}_{3}+\mathrm{H}_{2} \mathrm{O}$ were performed to investigate the phase change under repeated melting and crystallization transitions. Samples corresponding to the eutectics $E$ and e were subjected to 182 and 220 thermal cycles between $-20{ }^{\circ} \mathrm{C}$ and $40{ }^{\circ} \mathrm{C}$, respectively. Fig. 4 depicts seven pictures taken during a representative heating-cooling cycle.
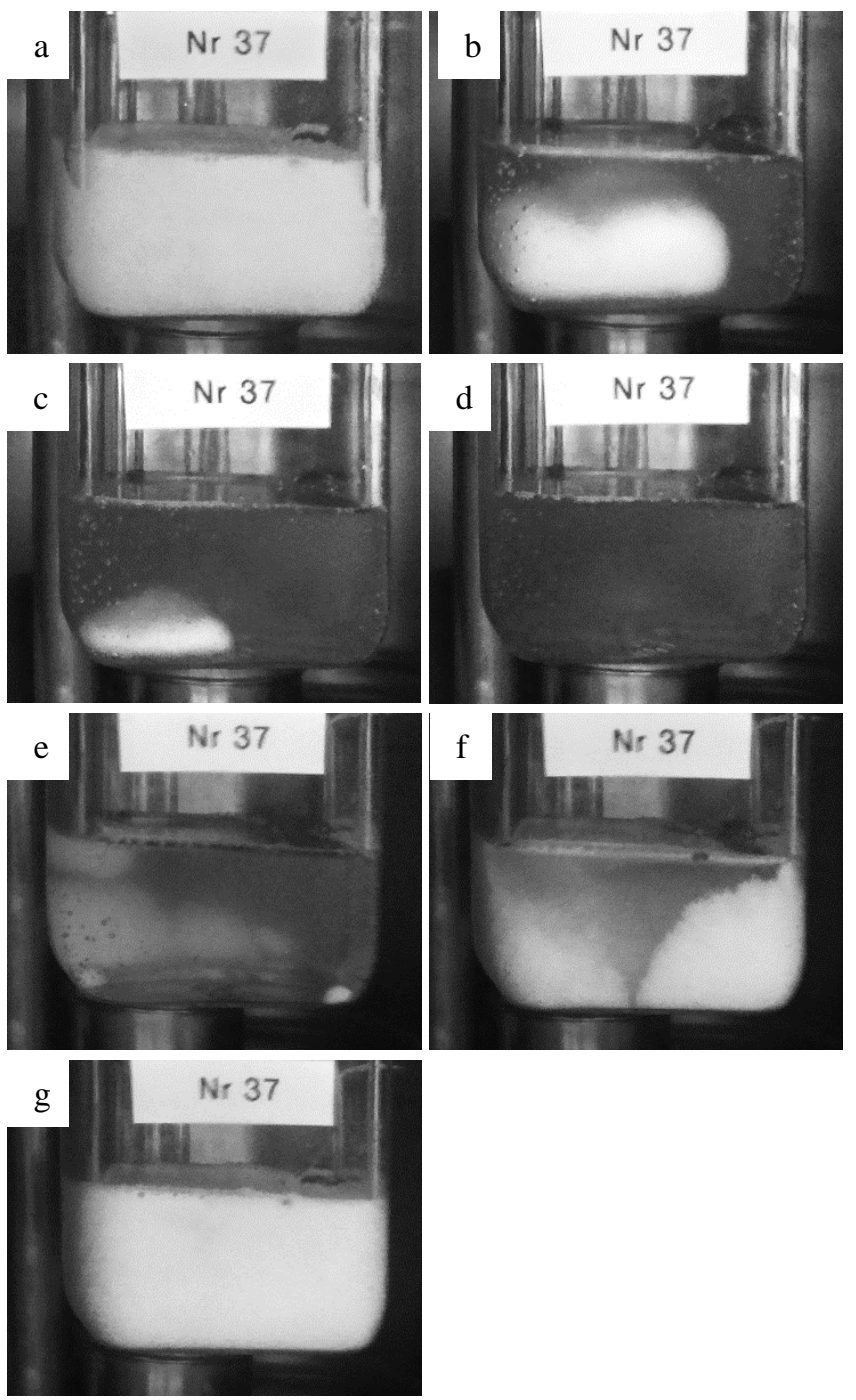

Fig. 4. Pictures of thermal cycling of a sample of the eutectic compositions $\mathrm{E}$ of the system $\mathrm{LiNO}_{3}+\mathrm{NH}_{4} \mathrm{NO}_{3}+\mathrm{H}_{2} \mathrm{O}$; melting (pictures a to $\mathrm{d}$ ) and crystallization (pictures $\mathrm{d}$ to $\mathrm{g}$ )
Pictures of the thermal cycling tests on the sample corresponding to eutectic e are similar to the pictures presented in Fig. 4. For both eutectic samples E and e, no solid sediment is visible after thermal cycling. The absence of solid material at a temperature well above the calculated and experimentally verified eutectic temperature indicates that no phase separation occurred due to the applied thermal cycling procedure. The spherical shape of the growing crystals during the crystallization process (cf. Fig. 4 e and f) is typical for eutectic mixtures. In addition, the crystals growing at different locations within the sample container exhibit a comparable crystallization speed. Thus, it is concluded that the same crystalline eutectic is formed throughout the sample upon crystallization.

\section{CONCLUSIONS}

In order to develop PCM based on salt hydrate mixtures, solid-liquid phase diagrams of ternary salt hydrate mixtures have been predicted using the modified BET model. Thereby, ternary and pseudo-binary eutectics have been identified. DSC measurements were performed to check the calculated compositions of identified eutectics. If a single melting transition within a relatively narrow temperature range is observed, the predicted eutectic composition is successfully verified. Successfully verified eutectics were subsequently subjected to thermal cycling stability tests. This line of development approach has been illustrated with the two eutectics of the ternary system $\mathrm{LiNO}_{3}+\mathrm{NH}_{4} \mathrm{NO}_{3}+\mathrm{H}_{2} \mathrm{O}$.

During the project period, 44 ternary solid-liquid phase diagrams of mixtures of salt hydrates and salts were calculated, and the compositions and melting temperatures of 151 ternary or pseudo-binary eutectics were predicted. To verify the calculations, 40 eutectics were experimentally examined via differential scanning calorimetry. Subsequently, 16 verified eutectics were subjected to thermal cycling stability tests over a prolonged period. Up to now, 7 eutectics turned out to be thermally cycling stable. In the assessment of the thermal cycling stability, special attention was paid to the visual detection of a possible phase separation. Thermal cycling stability tests under application-oriented conditions and the visual examination for phase separation allow for reliable evaluation of the long-term stability of salt-water based PCM. In the future, the developed method can be used to provide cost-effective PCM with high energy densities for energy-relevant temperature ranges.

\section{ACKNOWLEDGMENT}

This work is part of the project properPCM and was supported by the German Federal Ministry of Economic Affairs and Energy under the project code 03ET1342A. The responsibility for the content of this publication is with the authors.

\section{REFERENCES}

[1] H. Mehling and L. F. Cabeza, Heat and cold storage with PCM - An up to date introduction into basics and applications, 1st ed., Berlin: Springer, 2008.

[2] G. A. Lane, Solar Heat Storage: Leatent heat material volume II, Boca Raton, Florida: CRC Press, Inc., 1986.

[3] H. Schmit, C. Rathgeber, P. Hoock, and S. Hiebler, "Critical review on measured phase transition enthalpies of salt hydrates in the context of solid-liquid phase change materials," Thermochim. Acta, vol. 683, 178477,2019 
[4] M. Kenisarin and K. Mahkamov, "Salt hydrates as latent heat storage materials: Thermophysical properties and costs," Sol. Energy Mater. Sol. Cells, vol. 145, pp. 255-286, 2016.

[5] B. Zalba, J. M. Marın, L. F. Cabeza, and H. Mehling, "Review on thermal energy storage with phase change: materials, heat transfer analysis and applications," Appl. Therm. Eng., vol. 23(3), pp. 251-283, 2003.

[6] W. Voigt and D. Zeng, "Solid-liquid equilibria in mixtures of molten salt hydrates for the design of heat storage materials," Pure Appl. Chem., vol. 74(10), pp. 1909-1920, 2002.

[7] D. Zeng, "Thermodynamische Modellierung von Salz-WasserSystemen von der Lösung bis zur Salzschmelze, " Doctoral Thesis, TU Bergakademie Freiberg, 2003.

[8] W. Voigt, "Calculation of salt activities in molten salt hydrates applying the modified BET equation, I: Binary systems," Monatsh. Chem., vol. 124(8-9), pp. 839-848, 1993.

[9] R. H. Stokes and R. A. Robinson, "Ionic hydration and activity in electrolyte solutions," J. Am. Chem. Soc., vol. 70(5), pp. 1870-1878, 1948.

[10] M. R. Ally and J. Braunstein, "Statistical mechanics of multilayer adsorption: electrolyte and water activities in concentrated solutions," J. Chem. Thermodyn., vol. 30, pp. 49-58, 1998.

[11] C. Rathgeber, H. Schmit, S. Hiebler, and W. Voigt, "Application of the modified BET model to concentrated salt solutions with relatively high water activities: Predicting solubility phase diagrams of $\mathrm{NaCl}+\mathrm{H}_{2} \mathrm{O}$,
$\mathrm{NaCl}+\mathrm{LiCl}+\mathrm{H}_{2} \mathrm{O}$, and $\mathrm{NaCl}+\mathrm{CaCl}_{2}+\mathrm{H}_{2} \mathrm{O}$," Calphad, vol. 66, pp. 101633, 2019.

[12] F. P. Hall, H. Insley, E. M. Levin, H. F. McMurdie, and C.R. Robbins, "General discussion of phase diagrams," Phase Diagrams for Ceramists, vol. 1, pp. 5-36, 1964.

[13] B. Li, D. Zeng, X. Yin, and Q. Chen, "Theoretical prediction and experimental determination of room-temperature phase change materials using hydrated salts as agents," J. Therm. Anal. Calorim., vol. 100, pp. 685-693, 2010.

[14] IEA SHC Task 42 / ECES Annex 29, http://task42.iea-shc.org/

[15] A. Lazaro, C. Peñalosa, A. Solé, G. Diarce, T. Haussmann et al., "Intercomparative tests on phase change materials characterisation with differential scanning calorimeter," Appl. Energy, vol. 109, pp. 415-420, 2013.

[16] S. Gschwander, T. Haussmann, G. Hagelstein, C. Barreneche, G. Ferrer et al., "Standardization of pcm characterization via DSC," Refrigeration Science and Technology, pp. 70-75, 2016.

[17] C. Rathgeber, L. Miró, L. F. Cabeza, and S. Hiebler, "Measurement of enthalpy curves of phase change materials via DSC and T-History: When are both methods needed to estimate the behaviour of the bulk material in applications?," Thermochim. Acta, vol. 596, pp. 79-88, 2014.

[18] H. Schmit, S. Pöllinger, W. Pfeffer, and S. Hiebler, "Calorimetric and theoretical determination of the concentration dependent enthalpy change around $\mathrm{CaBr}_{2} \cdot 6 \mathrm{H}_{2} \mathrm{O}$," Thermochim. Acta, vol. 609, pp. 20-30, 2015. 